\title{
Highly Efficient Adsorption of Copper Ions by a PVP-Reduced Graphene Oxide Based On a New Adsorptions Mechanism
}

\author{
Yongji Zhang ${ }^{1}$, HuiJuan $\mathrm{Chi}^{1}$, WenHui Zhang ${ }^{1}$, Youyi Sun ${ }^{1,2, *}$, Qing Liang ${ }^{1}, \quad$ Yu Gu ${ }^{2, *}$, Riya Jing ${ }^{1}$
}

(Received 19 September 2013; accepted 25 November 2013; published online 13 January 2014)

\begin{abstract}
Polyvinylpyrrolidone-reduced graphene oxide was prepared by modified hummers method and was used as adsorbent for removing $\mathrm{Cu}$ ions from wastewater. The effects of contact time and ions concentration on adsorption capacity were examined. The maximum adsorption capacity of $1689 \mathrm{mg} / \mathrm{g}$ was observed at an initial $\mathrm{pH}$ value of 3.5 after agitating for $10 \mathrm{~min}$. It was demonstrated that polyvinylpyrrolidone-reduced graphene oxide had a huge adsorption capacity for $\mathrm{Cu}$ ions, which was 10 times higher than maximal value reported in previous works. The adsorption mechanism was also discussed by density functional theory. It demonstrates that $\mathrm{Cu}$ ions are attracted to surface of reduced graphene oxide by $\mathrm{C}$ atoms in reduced graphene oxide modified by polyvinylpyrrolidone through physisorption processes, which may be responsible for the higher adsorption capacity. Our results suggest that polyvinylpyrrolidone-reduced graphene oxide is an effective adsorbent for removing $\mathrm{Cu}$ ions in wastewater. It also provides a new way to improve the adsorption capacity of reduced graphene oxide for dealing with the heavy metal ion in wastewater.
\end{abstract}

Keywords: Polyvinylpyrrolidone; Graphene oxide; Cu ions; Wastewater treatment; Adsorption mechanism; Density functional theory

Citation: Yongji Zhang, HuiJuan Chi, WenHui Zhang, Youyi Sun, Qing Liang, Yu Gu and Riya Jing, "Highly Efficient Adsorption of Copper Ions by a PVP-Reduced Graphene Oxide Based On a New Adsorptions Mechanism", Nano-Micro Lett. 6(1), 80-87 (2014). http://dx.doi.org/10.5101/nml.v6i1.p80-87

\section{Introduction}

Electroplating is a major polluting industry due to easily discharging of toxic metals in effluents [1]. Tracing amounts of some metal ions such as copper, zinc, iron and cobalt is required by organisms as cofactors with enzymatic activities. However, the excess of the heavy metal ions will cause serious potential problems on living organisms due to their high toxicity, carcinogenic and bioaccumulation [2]. The content of The World Health Organization (WHO) recommended the maximum acceptable concentration of $\mathrm{Cu}$ ions in drinking water is $1.5 \mathrm{mg} / \mathrm{L}$ [2]. Lots of treatment methods (such as chemical precipitation, ion exchange, electrol- ysis, reverse osmosis, adsorption, etc.) have been investigated and applied to remove $\mathrm{Cu}$ ions [3-7]. Among these methods, adsorption is considered to be an economical, efficient and promising method for $\mathrm{Cu}$ ions treatment in wastewater [8]. Till now, a lot of adsorbents, for example, agricultural wastes, kaolinite, natural zeolites, clays, chitosan, magnetic particles, active carbon, carbon nanotubes, graphene oxide have been investigated to remove $\mathrm{Cu}$ ions from aqueous solution [9-17]. However, further applications of these materials are limited due to the lower adsorption capacities or efficiencies $(<200 \mathrm{mg} / \mathrm{g})$.

Graphene was considered as a good nanomaterial for removing metal ions due to its high surface area, an-

\footnotetext{
${ }^{1}$ Research Center for Engineering Technology of Polymeric Composites of Shanxi Province, North University of China, Taiyuan 030051, P.R. China

${ }^{2}$ Department of Mechanics, Beijing Jiaotong University, Beijing 100044, P.R. China

*Corresponding author. E-mail: syyi@mail.ustc.edu.cn (Y. Y. Sun), yugu@bjtu.edu.cn (Y. Gu)
} 
tibacterial property and lower cytotoxicity [18-26]. In recent years, graphene nanosheets (GNSs) were fabricated by the vacuum-promoted exfoliation method at low-temperature and used to adsorb $\mathrm{Pb}$ ions and the adsorption capacity of about $40 \mathrm{mg} / \mathrm{g}$ was obtained [24]. Chemically reduced and functionalized graphene oxide (GO) was also prepared by refluxing of GO with ethylenediamine (ED) using dimethyl formamide (DMF) as solvent. The resulting adsorbent (ED-DMF-RGO) with amine group was used to remove $\mathrm{Cr}$ ions from aqueous solution and about $92.5 \mathrm{mg} / \mathrm{g}$ of adsorption capacity was found [25]. Kwang S. Kim reported the preparation of PPy-reduced GO (PPy-rGO), which has highly selective adsorption capacity for $\mathrm{Hg}$ ions. The results showed that the adsorption capacity was about $980 \mathrm{mg} / \mathrm{g}$ and $58 \mathrm{mg} / \mathrm{g}$ for removing $\mathrm{Hg}$ ions and $\mathrm{Cu}$ ions, respectively [26]. This value of $58 \mathrm{mg} / \mathrm{g}$ for $\mathrm{Cu}$ ions is relatively lower compared with those for other metal ions. How to improve the adsorption capacities for $\mathrm{Cu}$ ions is then becoming an important and interesting issue. Moreover, despite of many studies in this field, it can be noticed that very few and isolated fact are available on how to affect adsorption capacities of graphene materials, that is, the adsorption mechanism is less discussed.

The aim of this paper is to improve $\mathrm{Cu}$ ions adsorption capacity of graphene. The adsorption mechanism was also discussed. Polyvinylpyrrolidone (PVP) was chosen as the reductant and dispersant for preparing the reduced graphene oxide (rGO) by using modified hummers method.

\section{Experimental}

\section{(1) Materials}

Nature graphite flakes (325 mesh, 99.8\%), cupric chloride dihydrate $\left(\mathrm{CuCl}_{2} \cdot 2 \mathrm{H}_{2} \mathrm{O}\right)$, sodium hydroxide $(\mathrm{NaOH})$, hydrochloric acid $(\mathrm{HCl})$, and other chemicals and reagents used in this work are all in analytical grade. Deionized water was used for preparation, dilution and analytical purpose.

(2) Preparation of polyvinylpyrrolidone-reduced graphene oxide (PVP-rGO)

PVP-rGO was prepared from natural graphite by modifying the well-known hummers method [18]. Firstly, $5 \mathrm{~g}$ graphite was oxidized by $250 \mathrm{~mL} \mathrm{H}_{2} \mathrm{SO}_{4}$ $(98 \%)$ in ice-water bath with stirring for $30 \mathrm{~min}$. A 15 g $\mathrm{KMnO}_{4}$ was gradually added with stirring and cooling for $30 \mathrm{~min}$. Subsequently, $30 \mathrm{~g} \mathrm{NaNO}_{3}$ was added with continuous stirring at $30^{\circ} \mathrm{C}$ for $1 \mathrm{~h}$. Then, 900 $\mathrm{mL}$ deionized water was added with continuous stirring at $90^{\circ} \mathrm{C}$ for $30 \mathrm{~min}$. Finally, $30 \mathrm{~mL} \mathrm{H}_{2} \mathrm{O}_{2}$ solution $(30 \%)$ was slowly added to the mixture. The color of the dispersion turned from black to yellow. The synthetic product was filtered and washed with $\mathrm{HCl}(5.0 \mathrm{wt} \%)$ and deionized water for several times, respectively. The product was dried at $60^{\circ} \mathrm{C}$ and then the graphite oxide solid was obtained.

The GO solution with high stabilization was prepared by dispersing $0.5 \mathrm{~g}$ graphite oxide solid powder in 200 $\mathrm{mL}$ deionized water and ultrasounded under $150 \mathrm{~W}$ for $1 \mathrm{~h}$. A $0.25 \mathrm{~g} \mathrm{PVP}$ and $2.5 \mathrm{~mL}$ hydrazine hydrate were mixed in a $250 \mathrm{~mL}$ round-bottomed flask and then 100 $\mathrm{mL}$ above GO solution $(2.5 \mathrm{mg} / \mathrm{mL})$ was added. The mixture was gradually heated to $80^{\circ} \mathrm{C}$ and kept for 4 $\mathrm{h}$ under stirring. The color of the dispersion solution turned from yellow to black.

(3) Characterization

The X-ray diffraction (XRD) patterns of the samples were recorded with a Rigaku D/Max-2000 diffractometer (Japan) equipped with a $\mathrm{Cu} \mathrm{KR}$ radiation source $(\lambda=0.15418 \mathrm{~nm})$. The scanning range was from $10^{\circ}$ to $80^{\circ}$ and the scanning interval was $0.5^{\circ}$.

Morphologies of the samples were studied by a Hitachi S-4800 scanning electron microscope (SEM) (Japan). The element composition was characterized by a Horiba EX-250 X-ray energy-dispersive spectrometer (EDX) associated with SEM.

Fourier Transform Infrared (FTIR) spectra were recorded using Nicolet 5700 Infrared Spectrometer (USA) in the mid infrared range $\left(4000-400 \mathrm{~cm}^{-1}\right)$.

(4) Adsorption Experiments

The $\mathrm{Cu}$ ions solution $(17.5 \mathrm{mg} / \mathrm{mL})$ was prepared by dissolving $50 \mathrm{~g}$ cupric chloride dihydrate $\left(\mathrm{CuCl}_{2} \cdot 2 \mathrm{H}_{2} \mathrm{O}\right)$ in $1000 \mathrm{~mL}$ deionized water. The other solutions with various concentrations were adjusted by successive dilution. The effect of contact time on $\mathrm{Cu}$ ions adsorption was investigated by setting different adsorption time (from 2 to $30 \mathrm{~min}$ ) with the dosage of $2.5 \mathrm{mg} / \mathrm{mL}$ and $\mathrm{pH}$ of 3.5. To evaluate the effect of initial $\mathrm{Cu}$ ions concentration, the experiments were conducted at initial $\mathrm{Cu}$ ions concentrations from 3.5 to $17.5 \mathrm{mg} / \mathrm{mL}$ at 2.5 $\mathrm{mg} / \mathrm{mL}$ dosage and $\mathrm{pH} 3.5$ for $10 \mathrm{~min}$.

The solution was then filtered and the residual $\mathrm{Cu}$ ions concentration was measured using an atomic absorption spectrophotometer (GBC, Avanta) at a $\lambda=$ $324.7 \mathrm{~nm}$. The amount of $\mathrm{Cu}$ ions adsorbed at equilibrium $q_{\mathrm{e}}(\mathrm{mg} / \mathrm{g})$ was obtained from the equation,

$$
q_{\mathrm{e}}=\left(C_{\mathrm{o}}-C_{\mathrm{e}}\right) W / w
$$

Where $C_{\mathrm{o}}, C_{\mathrm{e}}, W$ and $w$ represent the initial ion concentrations $(\mathrm{mg} / \mathrm{g})$, equilibrium $\mathrm{Cu}$ ions concentrations $(\mathrm{mg} / \mathrm{g})$, the solvent mass $(\mathrm{g})$ and the adsorbent mass (g), respectively.

\section{Results and discussion}

The X-ray diffraction results of graphite and PVPrGO are shown in Fig. 1. The graphite appeared a strong peak at $26.4^{\circ}$ corresponding to (002) lattice 
planes [27]. However, a broad diffraction peak at $25.8^{\circ}$ was observed on PVP-rGO powder, which was attributed to (002) lattice planes of the graphene [24]. The plane space $d$ was calculated to be $0.36 \mathrm{~nm}$, which was slightly larger than $0.34 \mathrm{~nm}$ of graphite (JCPDS No. 75-1621) [27]. These results indicate the formation of rGO prepared from nature graphite [18].

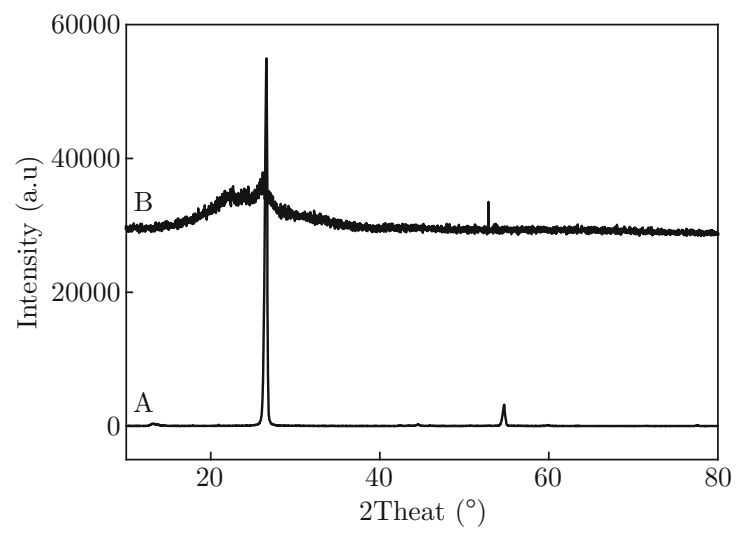

Fig. 1 XRD of (A) graphite and (B) PVP-rGO.

The FT-IR spectrum of PVP-rGO is shown in Fig. 2. The IR spectrum of rGO was also measured as a comparison, in which two absorptions bands at $1485 \mathrm{~cm}^{-1}$ and $1160 \mathrm{~cm}^{-1}$ were ascribed to $\mathrm{C}=\mathrm{C}$ conjugation and $\mathrm{C}-\mathrm{C}$ vibrations in graphene skeleton [28]. Some new absorption peaks of $1335 \mathrm{~cm}^{-1}, 1596 \mathrm{~cm}^{-1}$ and 1237 $\mathrm{cm}^{-1}$ were observed on PVP-rGO sample, which was caused by the PVP [29]. The inset in Fig. 2 shows the snapshot of rGO and PVP-rGO aqueous solution. Both of them were ultrasonically dispersed for $10 \mathrm{~min}$

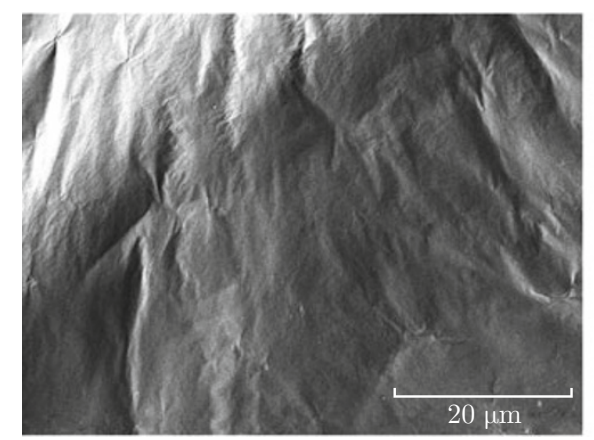

(a)

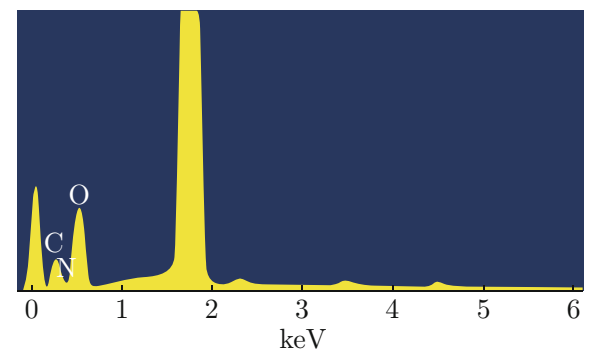

(c) in double-distilled water and then standed for $30 \mathrm{~min}$. It can be seen that the PVP-rGO solution is more stable and homogeneous compared with that of rGO. This is crucial to further applications.

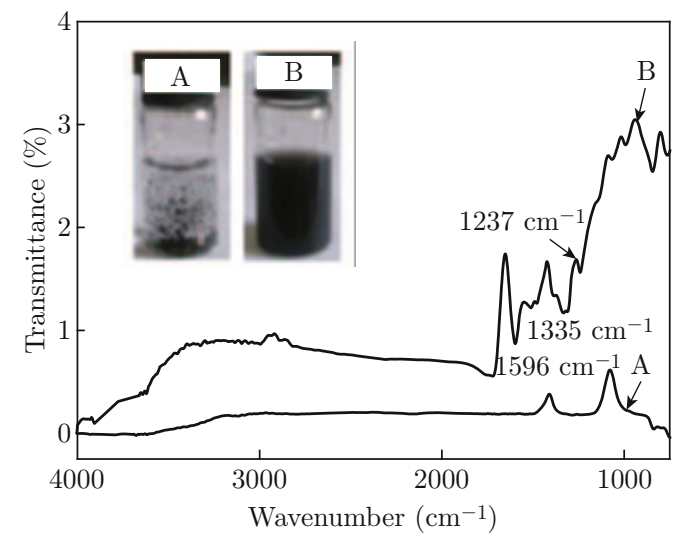

Fig. 2 FT-IR spectra of (A) rGO and (B) PVP-rGO. Inset is snapshot of (A) rGO aqueous solution and (B) PVP-rGO aqueous solution.

The SEM images of PVP-rGO adsorption results of $\mathrm{Cu}$ ions before and after are displayed in Fig. 3. The surface before adsorption is smooth (Fig. 3(a)), whereas, it contains many small particles after adsorption (Fig. 3(b)). EDX performed on these two samples are shown in Fig. 3(c) and 3(d). The weight fractions of elements before and after adsorption $\mathrm{Cu}$ ions are shown in Table 1. No Cu element was observed before adsorption, whereas, $43 \mathrm{wt} \%$ of $\mathrm{Cu}$ was measured after adsorption. The weight ratio of $\mathrm{Cu}$ and PVP-rGO is about 1.15 .

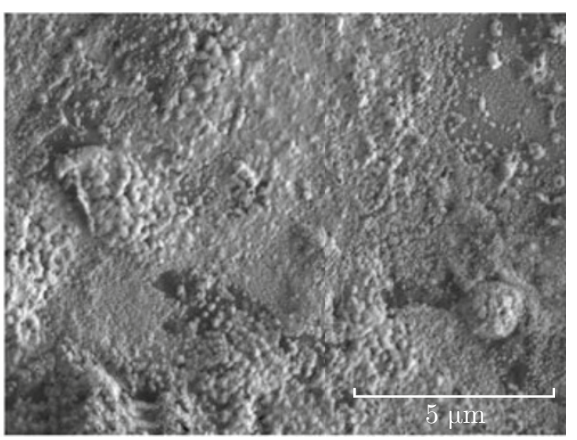

(b)

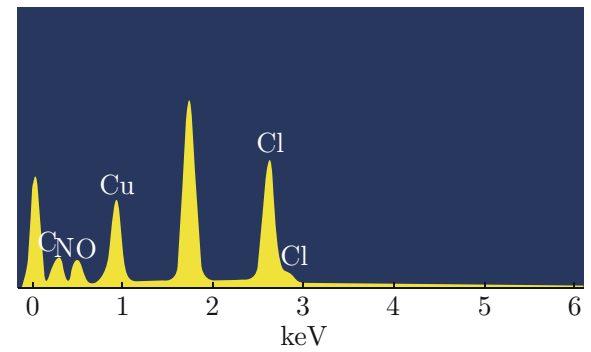

(d)

Fig. 3 SEM of (A) rGO and (B) PVP-rGO, EDX of (C) rGO and (D) PVP-rGO. 
Table 1 Element analysis of PVP-rGO before and after adsorption copper ions by EDX

\begin{tabular}{ccccccc}
\hline Element & $\mathrm{C}$ & $\mathrm{N}$ & $\mathrm{O}$ & $\mathrm{Cu}$ & $\mathrm{Cl}$ & $\mathrm{Si}$ \\
\hline Before & 43.93 & 1.99 & 7.91 & - & - & 46.17 \\
After & 28.87 & 1.29 & 7.34 & 43.27 & 15.36 & 3.88 \\
\hline
\end{tabular}

The adsorption capacity of PVP-rGO as function of initial $\mathrm{Cu}$ ions concentration was investigated as shown in Fig. 4. It shows that the effect of initial concentration on adsorption capacity of PVP-rGO is slight. Generally, the adsorption capacity increased with an increase in initial $\mathrm{Cu}$ ions concentration in previous works [1216]. The reason is shown as follow: when the initial concentration of $\mathrm{Cu}$ ions was low $(<0.1 \mathrm{mg} / \mathrm{mL})$, the adsorption sites of adsorbents were not used fully and thus the adsorption uptake was low. So, the adsorption capacity increased with the increase of initial $\mathrm{Cu}$ ions concentration. Here, the different result was attributed to that the adsorption sites of PVP-rGO were almost used fully at high initial concentration of $3.5 \mathrm{mg} / \mathrm{mL}$, and so the adsorption capacity slightly increased with the increase of initial $\mathrm{Cu}$ ions concentration from 3.5 $\mathrm{mg} / \mathrm{mL}$ to $17.5 \mathrm{mg} / \mathrm{mL}$. In addition to this, it is also observed that the maximal adsorption capacity is about $1689 \mathrm{mg} / \mathrm{g}$ at the initial $\mathrm{Cu}$ ions concentration of 7.0 $\mathrm{mg} / \mathrm{mL}$. Table 2 is the comparison of adsorption capacity of PVP-rGO and other adsorbents for $\mathrm{Cu}$ ions. It can be seen that PVP-rGO has a relatively higher adsorption capacity of $\mathrm{Cu}$ ions compared with other adsorbents, and it is almost 10 times higher than maximal value reported in previous works [10-17, 26]. These results further indicate that the PVP-rGO owns high adsorption capacity of $\mathrm{Cu}$ ions.

Fig. 5(a) and 5(b) show the adsorption isotherms of PVP-rGO toward $\mathrm{Cu}$ ions and the effect of the initial concentration on the removal percentage of $\mathrm{Cu}$ ions by PVP-rGO using a $2.5 \mathrm{mg} / \mathrm{mL}$ adsorbent dose, respectively. As shown in Fig. 5(a), the adsorption capacity slightly increased with increasing equilibrium concentration. The result is attributed to high initial

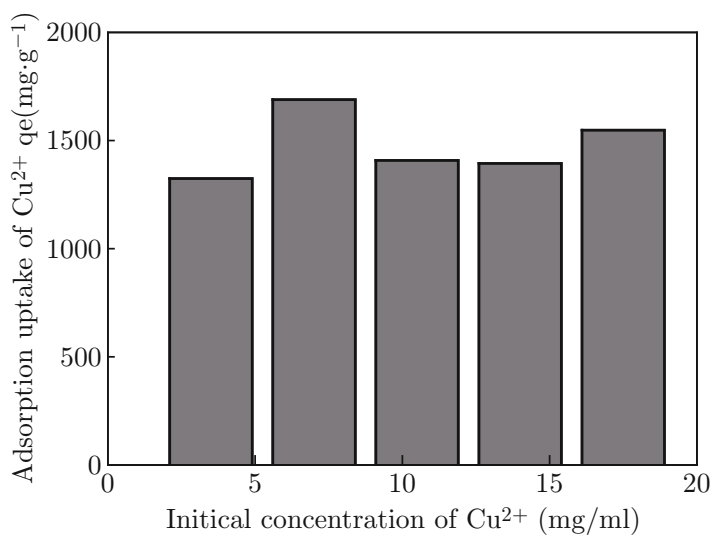

Fig. 4 Adsorption capacity of PVP-rGO as functions of initial $\mathrm{Cu}(\mathrm{II})$ concentration.
Table 2 Comparison of adsorption capacity and equilibrium time of various adsorbents for $\mathrm{Cu}^{2+}$

\begin{tabular}{lccc}
\hline Adsorbent & $\begin{array}{c}\text { Adsorption } \\
\text { capacity }(\mathrm{mg} / \mathrm{g})\end{array}$ & $\begin{array}{c}\text { Equilibrium } \\
\text { time (min) }\end{array}$ & Reference \\
\hline PVP-rGO & 1689.0 & 10 & This work \\
PPy-rGO & 58.0 & 20 & {$[26]$} \\
$\mathrm{GO}$ & 117.5 & 150 & {$[16]$} \\
$\mathrm{Fe}_{3} \mathrm{O}_{4} / \mathrm{GO}$ & 62.73 & 100 & {$[10]$} \\
& 18.26 & 20 & {$[11]$} \\
$\mathrm{Fe}_{2} \mathrm{O}_{3}$ nanotubes & 111.11 & 60 & {$[12]$} \\
$\mathrm{Ag}_{\text {carbon nanotubes }}$ & 58.02 & 120 & {$[13]$} \\
Dowex M-4195 & 110.9 & 300 & {$[14]$} \\
clays & 32.3 & 80 & {$[15]$} \\
fly ash & 221 & 20 & {$[17]$} \\
\hline
\end{tabular}
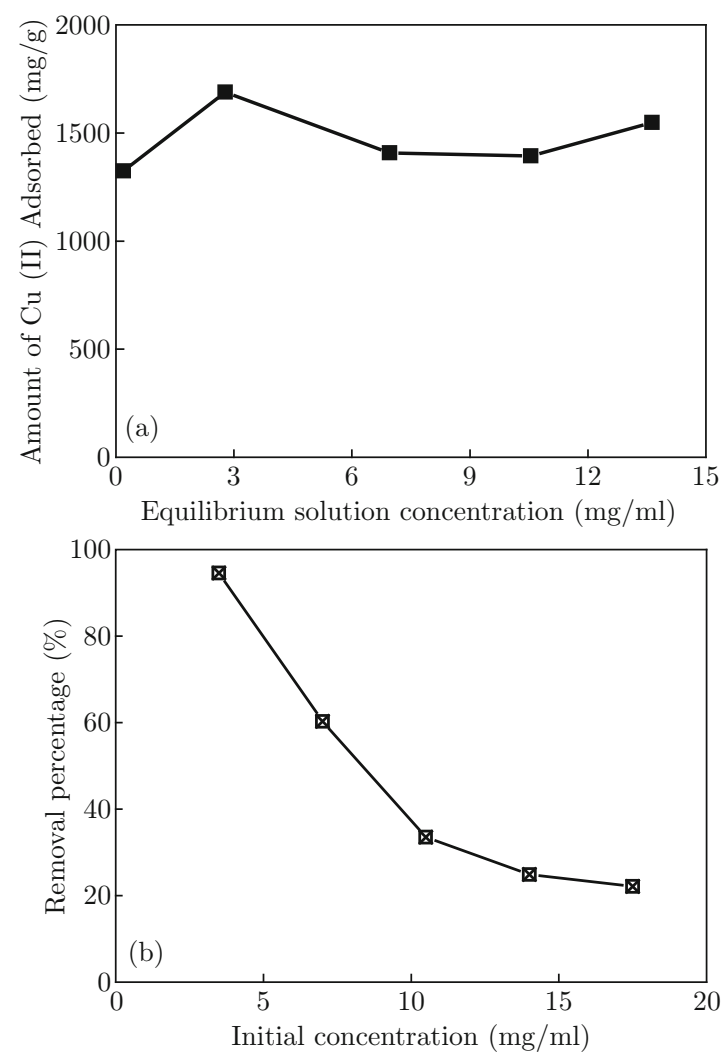

Fig. 5 (a) Adsorption isotherms of PVP-rGO toward $\mathrm{Cu}^{2+}$ and (b) Effect of initial concentration of $\mathrm{Cu}(\mathrm{II})$ on removal percentage.

concentration as well. At high initial solution concentration $(>3.5 \mathrm{mg} / \mathrm{mL})$, the total available adsorption sites are limited, and so the effect of equilibrium concentration on adsorption capacity is slight. The removal percentage of $\mathrm{Cu}$ ions decreased with increasing initial concentration as shown in Fig. 5(b). At low initial solution concentration, the surface area and the availability of adsorption sites are relatively high. At higher initial solution concentration, the total available adsorption sites are limited, thus resulting in a decrease in the percentage removal of adsorbate. 
Equilibrium time is another important parameter to heavy metals wastewater treatment process and also investigated as shown in Fig. 6. It clearly shows that the adsorption capacity of PVP-rGO slightly increases with the increase of contact time from 2 min to $10 \mathrm{~min}$. When the contact time further increases, the adsorption capacity is almost with no change. The result indicates the adsorption equilibrium to be about $10 \mathrm{~min}$. Table 2 also shows the comparison of equilibrium time of PVP-rGO and other adsorbents for $\mathrm{Cu}$ ions. It can be seen that PVP-rGO has a relatively more rapid adsorption of $\mathrm{Cu}$ ions compared with other adsorbents. This rapid adsorption indicated that the adsorption occurred mainly on the surface of the adsorbent, which was difficult to be observed in previous results [10-17, 26]. In addition to this, the adsorption reach equilibrium within few minutes is attributed to following two reasons. Firstly, the surface of PVP-rGO did almost not contain $\mathrm{COOH}$ or $-\mathrm{OH}$ group. So, the effect of $-\mathrm{COOH}$ or $-\mathrm{OH}$ on equilibrium time was slight. Secondly, the good stabilization and dispersion of PVP-rGO provide shorter time for the contact between adsorption sites and metal ions. As shown in inset of Fig. 6, the blue water containing $\mathrm{Cu}$ ions $(7.0 \mathrm{mg} / \mathrm{mL})$ change to colorless water after adsorption treatment for $2 \mathrm{~min}$. These results indicate that the PVP-rGO has high adsorption rate of $\mathrm{Cu}$ ions, which is also very important for wastewater treatment.

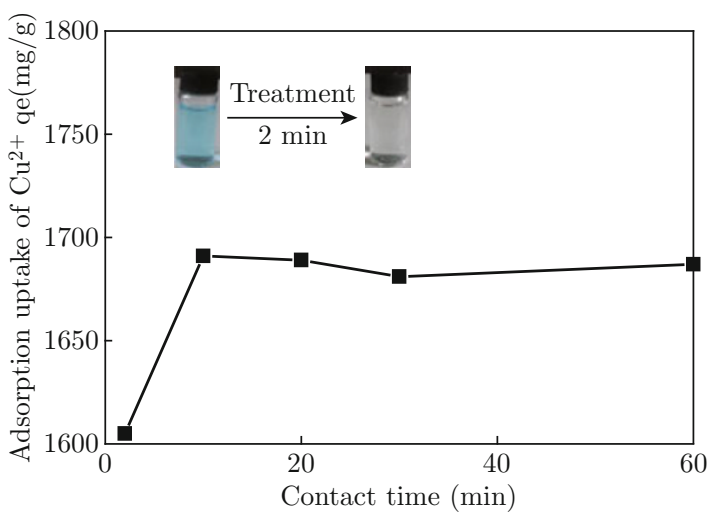

Fig. 6 Adsorption capacity of PVP-rGO as functions of contact time. The inset is snapshot of $\mathrm{Cu}$ ions aqueous solution after and before treatment.

\section{Mechanism of high efficient adsorption}

On the basis of the above experimental results, it is believed that the PVP-rGO is highly efficient in adsorption of $\mathrm{Cu}$ ions. It is well-known that there is strong interaction between functional groups (eg. $\mathrm{C}=\mathrm{O}$ and C-N) of PVP and metal ions [30-31], which provides lots of adsorption sites for removal of $\mathrm{Cu}$ ions. So, here the high adsorption capacity $(1689 \mathrm{mg} / \mathrm{g})$ of PVP-rGO was believed to come from the PVP coated on surface of rGO. The adsorption process was investigated by the
IR spectra of PVP-rGO after and before adsorption $\mathrm{Cu}$ ions as shown in Fig. 7. As shown in Fig. 7A, the absorption peaks at $1596 \mathrm{~cm}^{-1}$ and $1237 \mathrm{~cm}^{-1}$ are ascribed to the vibrations of $\mathrm{C}=\mathrm{O}$ and $\mathrm{C}-\mathrm{N}$ of $\mathrm{PVP}$ coated on surface of rGO. It clearly shows that these absorptions bands corresponding to $\mathrm{C}=\mathrm{O}$ and $\mathrm{C}-\mathrm{N}$ of $\mathrm{PVP}$ all disappear after the adsorption of $\mathrm{Cu}$ ions (in Fig. 7B). The result indicates that the PVP-rGO can adsorb the $\mathrm{Cu}$ ions by the interaction between functional groups $(\mathrm{C}=\mathrm{O}$ and $\mathrm{C}-\mathrm{N})$ of $\mathrm{PVP}$ and $\mathrm{Cu}$ ions. The adsorption mechanism is similar to that reported in previous works $[16,26]$, in which the functional group $(\mathrm{C}=\mathrm{O}, \mathrm{C}-\mathrm{N}$ and $\mathrm{OH})$ on surface of adsorbents is responsible to remove $\mathrm{Cu}$ ions.

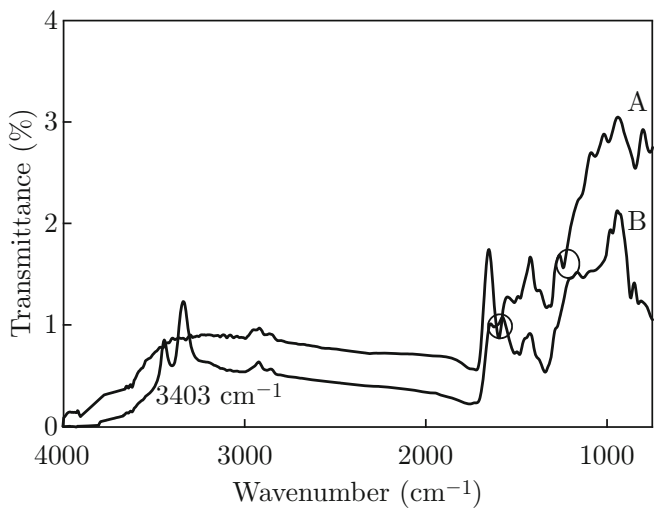

Fig. 7 IR spectra of PVP-rGO (A) before and (B) after adsorption copper ions.

However, according to the content of adsorption sites $(-\mathrm{C}=\mathrm{O}$ and $-\mathrm{C}-\mathrm{N})$ of PVP coated on surface of graphene by EDX, the theory value of maximal adsorption capacity is calculated to be about $350.0 \mathrm{mg} / \mathrm{g}$, which is far lower than experimental value of maximal adsorption capacity $(1689 \mathrm{mg} / \mathrm{g})$. In addition to this, the polypyrrole-rGO as adsorbents to remove the $\mathrm{Cu}$ ions from wastewater has been reported in the previous work [26]. Although there are similar chemical structure between polypyrrole and PVP, but the low adsorption capacity (ca. $58 \mathrm{mg} / \mathrm{g}$ ) of polypyrrole-rGO was observed for removal of $\mathrm{Cu}$ ions. So, what is the possible adsorption process for the high adsorption capacity $(1689 \mathrm{mg} / \mathrm{g})$ ? The traditional mechanism based on adsorption of chemical functional group coated on surface of graphene is difficult to explain it. The $\mathrm{C}$ atoms of graphene modified by $\mathrm{PVP}$ can attract $\mathrm{Cu}$ ions, which is possible reason for the high adsorption capacity. However, the possible adsorption process is rarely reported for removing heavy metal ions in wastewater.

To understand the high adsorption mechanism, the adsorption interaction between $\mathrm{Cu}$ ions and PVP-rGO were further discussions by density functional theory (DFT). The density functional theory (DFT) calculations were performed with CASTEP. In the DFT calculations, the lattice constant ( $a, b$ and $c$ ) of the 
graphene were designed as $2.46 \AA, 2.46 \AA$ and 3.14 $\AA$, respectively. At the same time, the vacuum layer with thickness of $2.0 \mathrm{~nm}$ was also doped into two layer graphene. And then, one $\mathrm{Cu}$ ion was put randomly on the $4 \times 4$ graphene super cell, in which the initial $\mathrm{Cu}$ ion-to-graphene distance was ca. $2.35 \AA$. Furthermore, exchange-correlation interactions were approximated by the generalized gradient approximation (GGA) with PBE parameterization. In the DFT calculations, Ultra-soft-pseudo potential was used. The k-point was set to $5 \times 5 \times 1$ for the Brillouin zone integration. A $350 \mathrm{eV}$ cut-off energy for the plane-wave basis set was used in all relaxation processes. Geometry relaxations were performed with the criterion that ionic force was smaller than $0.001 \mathrm{eVA}^{-1}$. Several positions of $\mathrm{Cu}$ ions relative to the PVP-rGO were considered near the three symmetry sites on the PVP-rGO to find the most favorable adsorption configuration (Fig. 8A - 8C). For convenience, the adsorption configurations shown in Fig. 8A - 8C are referred to as hollow $(\mathrm{H})$, bridge (B) and stack ( $\mathrm{T}$ ) configurations, respectively [32]. The result of optimization shows that the most stable atomic configurations for the $\mathrm{Cu}$ ions adsorbed on the PVP-rGO is stack. The potential energy of $\mathrm{Cu}$ ions/PVP-rGO system as function of distance between $\mathrm{Cu}$ ions and PVP-rGO was further calculated as shown in Fig. 9. Table 3 lists the potential energy and equilibrium $\mathrm{Cu}$ ions/PVP-rGO distance. In the $\mathrm{Cu}$ ions/PVPrGO system, all configurations gave rise to a different adsorption energy $\left(E_{\mathrm{b}}=0.249,0.234\right.$ and $0.072 \mathrm{eV}$ for $\mathrm{T}, \mathrm{B}$ and $\mathrm{H}$ configurations, respectively). Thus, this interaction is related to the cation- $\pi$ interaction between the $\mathrm{Cu}$ ions and the C-ring of the PVP-rGO. According to the contour plots for the total charge densities shown in Fig. 10, we can observe a homogeneous charge distribution in the PVP-rGO sheet and in the $\mathrm{Cu}$ ions without covalent or ionic bond. It indicates a physisorption between the $\mathrm{Cu}$ ions and C-ring of the PVP-rGO. According to Table 3, the shortest $\mathrm{Cu}$ ion-to- $\mathrm{G}$ distance $(\mathrm{d}=2.13 \AA)$ for the stack configurations is a little shorter than that of others configurations, and the adsorption energies is larger than that of others configurations. This is a consequence of coulomb repulsion

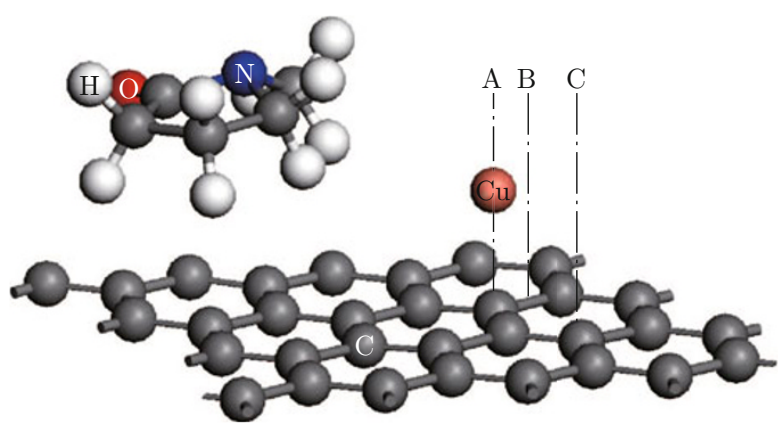

Fig. 8 Schematic view of $\mathrm{Cu}^{2+}$ adsorbed on PVP-rGO with different configurations: (A) stack, (B) bridge, (C) hollow.

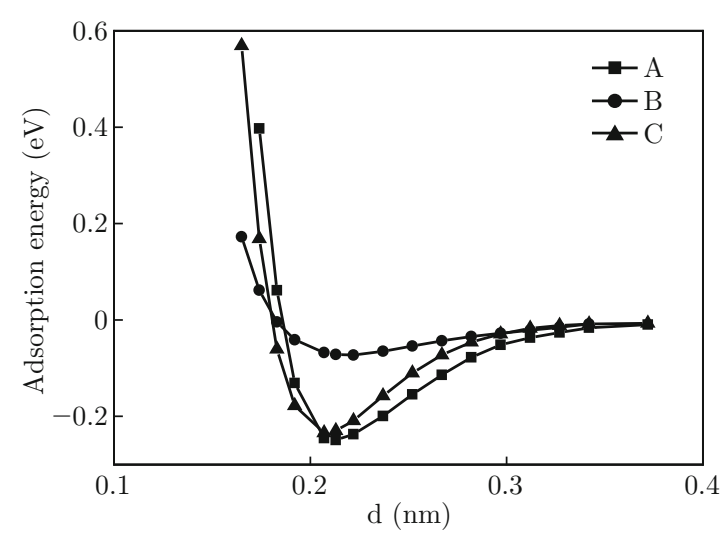

Fig. 9 Potential curve of the $\mathrm{Cu}$ ions and PVP-rGO with different configurations: (A) stack, (B) bridge, (C) hollow by DFT.

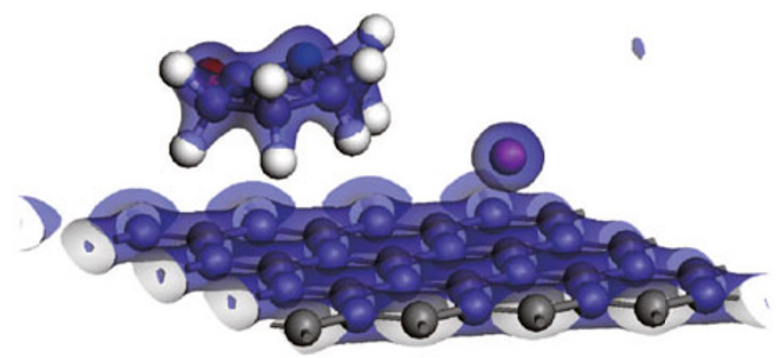

Fig. 10 Schematic view and contour plot of the total charge densities of $\mathrm{Cu}^{2+}$ interacting with PVP-rGO.

Table 3 Adsorption Energy and Equilibrium $\mathrm{Cu}^{2+}$ /PVP-rGO distance

\begin{tabular}{lccc}
\hline & $\mathrm{T}$ & $\mathrm{B}$ & $\mathrm{H}$ \\
\hline $\mathrm{Eb}(\mathrm{ev})$ & 0.249 & 0.234 & 0.073 \\
$\mathrm{~d}(\AA)$ & 2.13 & 2.25 & 2.17 \\
\hline
\end{tabular}

between the $\mathrm{Cu}$ ions and the $\mathrm{C}$ atoms on top of the PVP-rGO. To compensate for this repulsion, the cation- $\pi$ interaction between the C-rings generates the considerable adsorption energies observed (0.072 $-0.249 \mathrm{eV})$. These results indicate that the $\mathrm{Cu}$ ions can attract to the surface of PVP-rGO by the physisorption between $\mathrm{Cu}$ ion and $\mathrm{C}$ atom of graphene modified by PVP, which is the reason for the high adsorption capacity.

\section{Conclusions}

The present study indicates that PVP-rGO can be used as an effective adsorbent material for the treatment of $\mathrm{Cu}$ ions due to its adsorption sites (functional group of PVP) and large surface area of rGO. The adsorption capability of PVP-rGO can reach $1689 \mathrm{mg} / \mathrm{g}$, which is much higher than that of GO, carbon nanotubes and activated carbon. Furthermore, according to calculations of density functional theory, the $\mathrm{Cu}$ ions were adsorbed to the surface of PVP-rGO by 
the physisorption between $\mathrm{Cu}$ ions and the $\mathrm{C}$ atoms of graphene modified by PVP. The new adsorption process is the reason for the high adsorption capacity (1689 $\mathrm{mg} / \mathrm{g}$ ). So, it is very interesting to obtain a more effective interaction between this $\mathrm{Cu}$ ions and the $\mathrm{C}$ atom of graphene surface by chemically/physically modifying the rGO surface. These results will be helpful to further improve adsorption capacity of graphene materials for removal of heavy metal ions in wastewater.

\section{Acknowledgements}

The authors are grateful for the support by National Natural Science Foundation of China under grants (11202006), University's Science and technology exploiture of Shangxi Province (20121010) and the National Basic Research Program of China (G2010CB832701).

\section{References}

[1] Y. F. Zhang, Q. Chen, Z. D. Wang, G. Q. Zhang and Y. J. Ge, "Preparation of $\mathrm{Cr}$ hard coatings by ion beam assisted electron beam vapor deposition on Ni and Cu substrates", Surf. Coat. Tech. 201(911), 5190-1592 (2007). http://dx.doi.org/10.1016/ j.surfcoat. 2006.07.138

[2] T. S. Anirudhan, S. Jalajamony and S. S. Sreekumari, "Adsorptive removal of $\mathrm{Cu}(\mathrm{II})$ ions from aqueous media onto 4-ethyl thiosemicarbazide intercalated organophilic calcined hydrotalcite", J. Chem. Eng. Data 58(1), 24-31 (2013). http://dx.doi.org/10. 1021/je300536u

[3] F. Massimiliano, N. Biagio, T. Gelsomina and d'. Luca, "An environmental friendly cycle for $\mathrm{Cr}(\mathrm{III})$ removal and recovery from tannery wastewater", J. Environ. Manage. 117, 1-6 (2013). http://dx.doi.org/ 10.1016/j · jenvman. 2012.12.012

[4] T. B. Budak, "Removal of heavy metals from wastewater using synthetic ion exchange resin", Asian J. Chem. 25(8), 4207-4210 (2013).

[5] E-S. Z. El-Ashtoukhy, T. M. Zewail and N. K. Amin, "Removal of heavy metal ions from aqueous solution by electrocoagulation using a horizontal expanded $\mathrm{Al}$ anode", Desalin. Water Treat. 20(1-3), 72-79 (2010). http://dx.doi.org/10.5004/dwt.2010.1127

[6] R. M. Huang, J. Y. He, J. Zhao, Q. Luo and C. M. Huang, "Fenton-biological treatment of reverse osmosis membrane concentrate from a metal plating wastewater recycle system", Environ Technol. 32(5), 515-522 (2010). http://dx.doi.org/10.1080/ 09593330.2010 .504747

[7] H. Z. Mousavi and A. Asghari, "Removal of heavy metal ions in wastewater by Semnan natural zeolite", Asian J. Chem. 21(4), 2881-2886 (2009).

[8] Y. F. Lin, H. W.Chen, K. L. Lin, B. Y. Chen and C. Chiou, "Application of magnetic particles modified with amino groups to adsorb copper ions in aqueous solution", J. Environ. Sci. 23(1), 44-50 (2011). http: // dx.doi.org/10.1016/S1001-0742(10)60371-3

[9] A. K. Mark, "The removal of copper and nickel from aqueous solution using Y zeolite ion exchangers", Colloid. Surface. A 138(1), 11-20 (1998). http://dx.doi. org/10.1016/S0927-7757 (97)00078-2

[10] X. J. Hu, Y. G. Liu, H. Wang, A. W. Chen, G. M. Zeng, S. M. Liu, Y. M. Guo, X. Hu, T. T. Li, Y. Q. Wang, L. Zhou and S. H. Liu, "Removal of $\mathrm{Cu}(\mathrm{II})$ ions from aqueous solution using sulfonated magnetic graphene oxide composite", Sep. Purif. Technol. 108, 189-195 (2013). http://dx.doi.org/10.1016/j. seppur. 2013.02.011

[11] J. Li, S. W. Zhang, C.L. Chen, G.X. Zhao, X. Yang, J. X. Li and X. K. Wang, "Removal of $\mathrm{Cu}(\mathrm{II})$ and fulvic acid by graphene oxide nanosheets decorated with $\mathrm{Fe}_{3} \mathrm{O}_{4}$ nanoparticles", ACS Appl. Mater. Inter. 4(9), 4991-5000 (2012). http://dx.doi.org/10.1021/ am301358b

[12] A. Roy and J. T. Bhattacharya, "Removal of $\mathrm{Cu}(\mathrm{II})$, $\mathrm{Zn}(\mathrm{II})$ and $\mathrm{Pb}(\mathrm{II})$ from water using microwave-assisted synthesized maghemite nanotubes", Chem. Eng. J. 211, 493-500 (2012). http://dx.doi.org/10.1016/j. cej.2012.09.097

[13] D. K. Venkata Ramana, Jae Su Yu and K. Seshaiah, "Silver nanoparticles deposited multiwalled carbon nanotubes for removal of $\mathrm{Cu}(\mathrm{II})$ and $\mathrm{Cd}(\mathrm{II})$ from water: Surface, kinetic, equilibrium, and thermal adsorption properties", Chem. Eng. J. 223, 806-815 (2013). http://dx.doi.org/10.1016/j.cej.2013.03.001

[14] J. Gao, F. Q. Liu, P. P. Ling, J. T. Lei, L. J. Li, C. H. $\mathrm{Li}$ and $\mathrm{A}$. M. Li, "High efficient removal of $\mathrm{Cu}(\mathrm{II})$ by a chelating resin from strong acidic solutions: Complex formation and DFT certification", Chem. Eng. J. 222, 240-247 (2013). http://dx.doi.org/10.1016/j.cej. 2013.02 .055

[15] K. G. Bhattacharyya and S. S. Gupta, "Removal of $\mathrm{Cu}(\mathrm{II})$ by natural and acid-activated clays: An insight of adsorption isotherm, kinetic and thermodynamics", Desalination 272(1-3), 66-75 (2011). http://dx.doi. org/10.1016/j.desal.2011.01.001

[16] W. Q. Wu, Y. Yang, H. H. Zhou, T. T. Ye, Z. Y. Huang, R. Liu and Y. F. Kuang, "Highly efficient removal of $\mathrm{Cu}(\mathrm{II})$ from aqueous solution by using graphene oxide", Water Air Soil. Poll. 224(1), 1372(1-8) (2013). http://dx.doi.org/10. $1007 / \mathrm{s} 11270-012-1372-5$

[17] X. W. Wu, H.W. Ma, L.T.Zhang and F.J. Wang, "Adsorption properties and mechanism of mesoporous adsorbents prepared with fly ash for removal of $\mathrm{Cu}(\mathrm{II})$ in aqueous solution", Appl. Surf. Sci. 261, 902-907 (2012). http://dx.doi.org/10.1016/j.apsusc. 2012.08.122

[18] D. Li, M. B. MüLler, S.Gilje, R. B. Kaner and G. G. Wallace, "Processable aqueous dispersions of graphene nanosheets", Nat. Nanotechnol. 3(2), 101-105 (2008). http://dx.doi.org/10.1038/nnano.2007.451

[19] L. H. Aia, C. Zhang and Z. Chen, "Removal of methylene blue from aqueous solution by asolvothermal synthesized graphene/magnetite composite", J. Hazard. 
Mater. 192(3), 1515-1524 (2011). http://dx.doi.org/ $10.1016 / j$. jhazmat. 2011.06 .068

[20] T. S. Sreeprasad, S. S. Gupt, S. M. Maliyekkal and T. Pradeep, "Immobilized graphene-based composite from asphalt: Facile synthesis and application in water purification", J. Hazard. Mater. 246, 213220 (2013). http://dx.doi.org/10.1016/j.jhazmat. 2012.12 .022

[21] K. C. Kemp, H. Seema, M. Saleh and N. H. Le, "Environmental applications using graphene composites: water remediation and gas adsorption". Nanoscale 5(8), 3149-3171 (2013). http://dx.doi.org/10.1039/ c3nr33708a

[22] V. Georgakilas, M. Otyepka and A. B. Bourlinos, "Functionalization of Graphene: Covalent and NonCovalent Approaches, Derivatives and Applications", Chem. Rev. 112(11), 6156-6214 (2012). http://dx. doi.org/10.1021/cr3000412

[23] V. Chandra, J.Park and Y.Chun, "Water-Dispersible Magnetite-Reduced Graphene Oxide Composites for Arsenic Removal", ACS Nano 4(7), 3979-3986 (2010). http://dx.doi.org/10.1021/nn1008897

[24] Z. H. Huang, X. Y. Heng, W. Lv, M. Wang, Q. H. Yang and F. Y. Kang, "Adsorption of Lead(II) ions from aqueous solution on low-temperature exfoliated graphene nanosheets", Langmuir 27(12), 7558-7562 (2011). http://dx.doi.org/10.1021/la200606r

[25] Y. W. Zhang, H. L. Ma, J. Peng, M. L. Zhai and Z. $\mathrm{Z}$. $\mathrm{Yu}$, "Cr(VI) removal from aqueous solution using chemically reduced and functionalized graphene oxide", J. Mater. Sci. 48(5), 1883-1889 (2013). http:// dx.doi.org/10.1007/s10853-012-6951-8

[26] V. Chandra and K. S. Kim, "Highly selective adsorption of $\mathrm{Hg}^{2+}$ by a polypyrrole-reduced graphene oxide composite", Chem. Commun. 47(13), 3942-3944 (2011). http://dx.doi.org/10.1039/c1cc00005e
[27] K. Moon, J. H. Lee, R. S. Ruoff and H. Lee, "Reduced graphene oxide by chemical graphitization", Nat. commun. 1, 73(1-6) (2010). http://dx.doi.org/10.1038/ ncomms 1067

[28] Q. L Du, M. B. Zheng, L. F. Zhang, Y. W. Wang, J. H. Chen, L. P. Xue, W. J. Dai, G. B. Ji and J. M. Cao, "Preparation of functionalized graphene sheets by a low-temperature thermal exfoliation approach and their electrochemical supercapacitive behaviors", Electrochim. Acta 55(12), 3897-3903 (2010). http://dx. doi.org/10.1016/j.electacta.2010.01.089

[29] D. F. Han, C. S. Shan, L. P. Guo, L. Niu and D. $\mathrm{X}$. Han, "Electro-oxidation of ascorbic acid on PVPstabilized graphene electrode", Chem. Res. Chinese U. 26(2), 287-290 (2010).

[30] Q. F. Lu, J. Yu, J. Z. Gao, W. Yang and Y. Li, "Glowdischarge Electrolysis Plasma Induced Synthesis of Polyvinylpyrrolidone/Acrylic Acid Hydrogel and its Adsorption Properties for Heavy-metal Ions", Plasma Process. Polym. 8(9), 803-814 (2011). http://dx.doi. org/10.1002/ppap. 201000144

[31] J. H. Zhao, W. Z. Yuan, A. H. Xu, F. Ai, Y. W. Lu and Y. M. Zhang, "Perfluorinated sulfonic acid ionomer/poly(N-vinylpyrrolidone) nanofiber membranes: Electrospinning fabrication, water stability, and metal ion removal applications", React. Funct. Polym. 71(11), 1102-1109 (2011). http://dx. doi.org/10.1016/j.reactfunctpolym. 2011.08.007

[32] Y. H. Zhang, K. G. Zhou, K. F. Xie, H. L. Zhang, Y. Peng and C. W. Wang, "Tuning the magnetic and transport properties of metal adsorbed graphene by co-adsorption with 1,2-dichlorobenzene", Phys. Chem. Chem. Phys 14(33), 11626-11632 (2012). http://dx. doi.org/10.1039/c2cp41370a 